\title{
Intensive fish farming in the Philippines is detrimental to the reef-building coral Pocillopora damicornis
}

\author{
R. D. Villanueva*, H. T. Yap, M. N. E. Montaño \\ The Marine Science Institute, University of the Philippines, Diliman, 1101 Quezon City, Philippines
}

\begin{abstract}
To determine the effects of fish farm effluent on the reef-building species Pocillopora damicornis, we exposed different life stages of the coral to a gradient of effluent concentrations. After $81 \mathrm{~d}$ no juvenile coral survived at the Fish Farm site or at the site receiving intermediate concentrations, and survival rates were low $(<20 \%)$ at the site receiving minimal effluent concentrations and at the reference site. At the Fish Farm site, juveniles (on terracotta tiles) were completely overgrown by barnacles. Coral nubbins and mature colonies displayed similar survivorship trends along the effluent gradient, i.e. higher mortality with higher effluent concentrations. At the site of intermediate exposure, surviving nubbins had skeletal growth rates half of those from the site of minimal influence and from the reference site. The mean gross photosynthesis to respiration ratio of coral branches deployed at the fish farm was below the physiological compensatory value of 1 , whereas values of about 1 were attained at the sites of diminishing effluent influence. Reduced larval output in mature colonies exposed to intermediate and minimal concentrations of fish farm effluent were observed as compared to those from the reference site. No reproductive measurements could be conducted for colonies at the Fish Farm site, due to high mortality. At the larval stage, metamorphosis was diminished both on substrates collected from, and tiles conditioned in, the Fish Farm environment, compared to those from sites of diminishing effluent influence. Hence, many aspects of coral biology are impaired by exposure to effluent from intensive fish farming.
\end{abstract}

KEY WORDS: Fish farm effluent - Sedimentation - Nutrient enrichment - Pocillopora damicornis · Coral survivorship $\cdot$ Metamorphosis $\cdot$ Growth rate

Resale or republication not permitted without written consent of the publisher

\section{INTRODUCTION}

The health of coral reefs in the face of increasing anthropogenic influence on the environment has been a major focus of discussion in recent years (e.g. Nyström et al. 2000, Hughes et al. 2003), resulting in a consensus view of a global decline in coral reef ecosystems (Pandolfi et al. 2003). On a local scale the emerging coastal activity of fish farming is now increasingly regarded as a threat to the health of fringing coral reefs (Loya et al. 2004, Villanueva et al. 2005).

The impact of intensive fish farming on different coastal marine ecosystems results from the massive discharge into the environment of organic matter in the form of fish metabolic excreta (feces, etc.) and waste feed. The major environmental stressors on marine ecosystems attributed to intensive fish farming are sedimentation and eutrophication. Both of these are considered detrimental to many aspects of the biology of reef-building corals (Rogers 1990, Koop et al. 2001), as these organisms normally thrive in clear, nutrient-poor waters. These stressors are also the major components of terrestrial run-off, which likewise has a tremendous impact on coral reefs (Fabricius 2005).

To date there are few reports on the effects of fish farm effluent on reef-building corals. Pioneering investigations by Bongiorni et al. $(2003 a, b)$ revealed high survivorship and enhanced growth and reproduction in corals grown near fish farms compared to a refer- 
ence site. In contrast, Loya et al. (2004) reported on the detrimental effect of nutrient enrichment caused by fish farms on coral reproduction. These investigations aimed to determine the reproductive effects of intensive fish farming on the same coral species, at the same sites and during overlapping periods. These divergent conclusions are due to differences in experimental design and the interpretation of results (see Loya \& Kramarsky-Winter 2003, Rinkevich et al. 2003, Loya et al. 2005, Rinkevich 2005 for discussions).

Given the ongoing debate, more studies need to be conducted before intensive fish farming is blamed for the demise of nearby coral reefs (Wielgus 2003). Previous studies should be replicated, or their results considered in the design of future studies. Furthermore, other aspects of the biology and ecology of reef corals have to be given due attention (e.g. larval metamorphosis, coral spat survivorship and competition with organisms associated with fish farm environments).

We previously reported the detrimental effect of exposure to fish farm effluent on the survivorship of coral juveniles in a Philippine setting (Villanueva et al. 2005). Corals with different morphologies and across different taxa can display variations in susceptibility to stress, but working with juveniles should minimize the possible effects of variations in susceptibility to stress due to their small profile or size. This is the feature most likely to be affected by the intense sedimentation and competition with fast growing, encrusting invertebrates that are promoted by fish farm effluent. The negative impact of fish farm effluent on coral juveniles would have overwhelming consequences for the main-

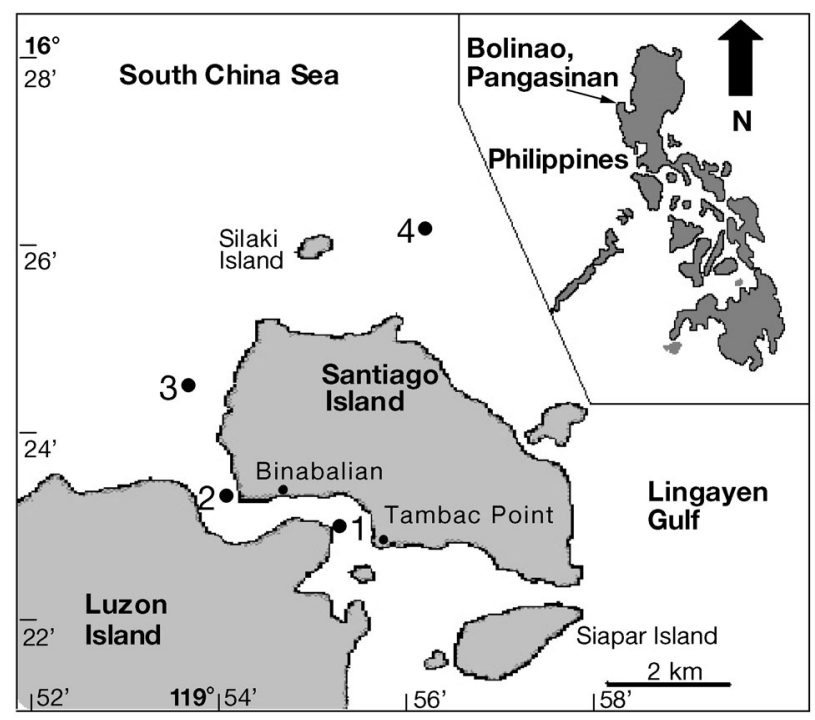

Fig. 1. Location of the study sites in Bolinao, Pangasinan, Philippines. (1) Fish Farm; (2) Tomasa; (3) Lucero; (4) Reference site tenance of a coral population, as low survivorship of juveniles in the natural reef is a barrier to population success (Babcock 1985, Sato 1985, Wilson \& Harrison 2005).

Here, we report on the effects of fish farm effluent on the biology of the reef-building species Pocillopora damicornis. We exposed different life stages of this coral to environments along the gradient of fish farm effluent concentrations. Vital life stage attributes and processes were assessed in order to draw general conclusions on the impact of fish farming on the biology of this coral. Furthermore, we document the water quality attributes of intensive fish farming which are collectively regarded to be responsible for the observed effects.

\section{MATERIALS AND METHODS}

Study sites. Bolinao is a coastal town in the northwestern Philippines harboring a complex of fringing coral reefs. Earlier documented anthropogenic stressors to the reefs included fishing malpractices, e.g. use of explosives and cyanide (McManus et al. 1992). During the late 1990's cage aquaculture of milkfish Chanos chanos proliferated in the channel between Santiago Island and mainland Luzon from Binabalian Loob to Tambac Point (Fig. 1). The cage density in this area is about $10 \mathrm{ha}^{-1}$. The stocking density is from 30000 to 60000 fish per cage, with each cage measuring about $800 \mathrm{~m}^{3}$. The effluent plume travels from the fish cages in a west-northwest direction out into the South China Sea (Udarbe-Walker \& Magdaong 2003). Following this coastal current pattern, we selected 3 sites to represent a gradient in effluent exposure: (1) Riripayan Point for maximal exposure (hereafter Fish Farm), (2) Tomasa Point for intermediate exposure, and (3) Lucero for minimal exposure (Fig. 1). The reference site (4) is at Malilnep Channel (hereafter Reference), which is the source reef for the colonies used in the field experiments. This site is virtually isolated from the effluent plume since a vast, shallow sandy flat separates it from Lucero.

Three replicate locations $50 \mathrm{~m}$ apart were chosen at each site. At Fish Farm 1 location is $20 \mathrm{~m}$ from the nearest fish cage. In all locations, a metal grid platform $(1 \times 1 \mathrm{~m})$ was put in place, and raised $30 \mathrm{~cm}$ above the substrate using metal bars. Each platform was situated approximately $2 \mathrm{~m}$ below the water surface.

Environmental monitoring. Environmental parameters at platform depth for each experimental site were determined twice: once at the start of the experiment (April 2004) and again 1mo later (May 2004). Sedimentation was measured using cylindrical sediment traps (5 $\mathrm{cm}$ diameter $\times 25 \mathrm{~cm}$ height). For each platform 2 
traps were deployed over a 2 d period to cover a complete tidal cycle. Sediments collected from traps were filtered using glass microfibre filters (GF/C, Whatman). The collected sediments were washed twice with $50 \mathrm{ml}$ distilled water and then dried in an oven at $70^{\circ} \mathrm{C}$ until constant weight. Sediments were further processed by ashing in a muffle furnace (Type 48000 Furnace, Thermolyne) at $600^{\circ} \mathrm{C}$ for $4 \mathrm{~h}$. The difference between the initial weight of the sediment and the resultant ash was considered to be the combustible, organic matter. Particulate organic matter (POM) flux was calculated by multiplying the percentage of organic matter in the sediment by the sedimentation rate. Total suspended solids were determined by filtering $900 \mathrm{ml}$ seawater, collected at platform depth, using cellulose nitrate membrane filters $(0.45 \mu \mathrm{m}$ pore size, Whatman). Collected solids were processed using the same method as described for sediments. Nutrients (ammonium and phosphate) were analyzed from filtered $(0.45 \mu \mathrm{m})$ water samples collected at platform depth following the procedures described in Hansen \& Koroleff (1999).

Net primary productivity and respiration of sitecollected seawater was determined (June 2004) as changes in dissolved oxygen (DO) levels over $1 \mathrm{~h}$ under light and dark conditions, respectively. Seawater samples (300 ml) were incubated in DO bottles submerged in a water bath $\left(28\right.$ to $\left.30^{\circ} \mathrm{C}\right)$. Primary productivity experiments were run outdoors under clear skies between 10:00 and 14:00 h. A layer of black netting was used to cover the incubation bin in order to obtain light intensities between 1500 and $2200 \mu \mathrm{E} \mathrm{m} \mathrm{m}^{-2} \mathrm{~s}^{-1}$. Light intensity was measured every 5 min, using a LI193SA spherical quantum sensor attached to a LI-1400 data logger (LI-COR). The range of light intensity employed was above the light saturation level for photosynthesis (Chalker et al. 1983) hence, production was considered maximal. Respiration measurements were run in a closed cabinet (indoors), with the incubation bin cover of black plastic. DO readings, before and after each incubation, were made with a YSI 58 Dissolved Oxygen Meter and YSI 5750 BOD Probe.

In situ light intensity was measured at approximately midday as described above. The average of 10 consecutive readings ( 1 every 10 to $15 \mathrm{~s}$ ) was obtained with each measurement. The value reported is the percentage of the surface irradiance that reaches platform level (i.e. $2 \mathrm{~m}$ depth) as indicator of water transparency. DO readings were performed as described above, but with a YSI 5718 Field Probe. DO measurement was not conducted in April due to instrument unavailability, necessitating a second measurement in June. The average of 3 readings represents the DO concentration in each replicate location. Water motion was measured by the clod-card technique (Doty 1971) with 2 cards deployed per platform over a $48 \mathrm{~h}$ period. Clod cards were calibrated by immersing 2 cards in 75 l seawater (34\%o salinity, 3 replicates). Salinity was measured using a Reichert (Brix) temperature-compensated salinometer (Cambridge Instruments).

Collection of coral and coral larvae. Mature colonies, 7 to $15 \mathrm{~cm}$ diameter, of Pocillopora damicornis were collected from the reef slope and flat (1 to $3 \mathrm{~m}$ depth) at Malilnep Channel (Reference Site; Fig. 1). The corals were transported to the Bolinao Marine Laboratory (University of the Philippines), maintained in holding tanks in an outdoor hatchery facility and supplied with flow-through, sand-filtered seawater and aeration.

To collect planula larvae, 16 colonies were individually held in plastic translucent buckets. During the day, flow-through, sand-filtered seawater and aeration were supplied, while seawater inflow was cut off at night. The seawater in which the coral was incubated in the evening was filtered in the morning using a nylon screen (215 $\mu \mathrm{m}$ mesh) to collect any larvae that had been released. Larval collections were conducted between the first quarter and full moon, the peak in planulation of the species at the study site (R. D. Villanueva, M. N. E. Montaño \& H. T. Yap unpubl. data). Collected larvae were pooled, maintained in a glass dish with filtered seawater $(0.45 \mu \mathrm{m}, \mathrm{FSW})$ and held in an indoor culture facility with a 23 to $27^{\circ} \mathrm{C}$ temperature range under light furnished by a cool fluorescent lamp

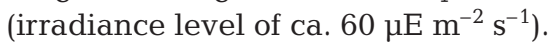

Larval metamorphosis on site-collected substrates (SCS) and site-conditioned tiles (SCT). Rocks and rubble (maximum dimension $4 \mathrm{~cm}$ ) were collected from each site at $2 \mathrm{~m}$ depth. Terracotta tiles $(4 \times 4 \mathrm{~cm})$ were deployed on the platforms at each site for at least 1 mo for conditioning (i.e. to allow coating with site-specific biota and sediment deposits). Prior to the experiment, substrates and tiles were examined to ensure that no coral spat was present. Metamorphic competency experiments were conducted in glass jars with $400 \mathrm{ml}$ FSW. In each jar $(n=10) 10$ freshly collected larvae and 1 tile or piece of natural substrate were added. Experimental jars were interspersed randomly in a culture shelf with light provided by a cool fluorescent lamp, attenuated by 2 layers of black netting for a resultant light intensity of about $20 \mu \mathrm{E} \mathrm{m} \mathrm{m}^{-2} \mathrm{~s}^{-1}$ at a 12:12 h light:dark regime. Temperature at the culture laboratory was maintained at 25 to $28^{\circ} \mathrm{C}$. Metamorphosis was examined after $48 \mathrm{~h}$. Metamorphosis is defined as the transformation of a larva from a free-swimming to a flattened, disc-shaped structure which is attached to the tile, substrate or glass (Heyward \& Negri 1999), or floats at the surface of the water (Epstein et al. 2001). Lost larvae may either have died or settled, but could not be located; hence, they were excluded in the com- 
putation of percent metamorphosis. Parallel incubations of larvae in FSW without tiles or substrates and with new, unconditioned tiles were conducted to serve as controls (10 jars each, 10 larvae per jar).

Preparation of coral spat and nubbins. Coral juveniles on terracotta tiles were prepared as described in Villanueva et al. (2005). Larvae of Pocillopora damicornis generally have a long onset of spontaneous metamorphosis (R. D. Villanueva unpubl. data). Therefore, we induced metamorphosis by increasing the density of larvae in cultures (>300 per $200 \mathrm{ml}$ FSW). Such a procedure probably promoted gregarious settlement (sensu Hadfield \& Paul 2001) or some chemical modification of the culture medium (e.g. depletion of DO that could trigger metamorphosis), but this mechanism needs further investigation.

Only 1 coral juvenile was retained per tile and the excess juveniles were scraped off prior to field deployment. The juveniles initially measured $2.2 \pm$ 0.7 (SD) $\mathrm{mm}$ in diameter and possessed $5 \pm 2$ polyps.

Coral nubbins on terracotta tiles were prepared as described in Davies (1995), using 1 to $2 \mathrm{~cm}$ branch tips from mature colonies. These were maintained in an outdoor culture facility for 1 mo for post-operative recovery. During this time, many of the nubbins underwent basal spreading (outgrowth), increasing attachment to the tile surface. Nubbins were weighed using the buoyant weight technique (Jokiel et al. 1978) prior to field deployment.

Field exposure of coral spat, nubbins and mature colonies. A total of 120 spats, 360 nubbins and 125 mature colonies (all individually tagged) were deployed at the experimental sites in April 2004. At each location (3 per site), 10 spats (on tiles), 30 nubbins (on tiles) and 10 or 11 mature colonies were tied to each metal platform using solid wire. The deployed tiles and coral colonies were not cleaned during the experiment. After $81 \mathrm{~d}$ the remaining corals were retrieved. Not all of the initially deployed corals, especially the nubbins, were recovered. This is probably due to their dislodgement by currents, browsing organisms or objects in the water such as sacks and monofilament lines (particularly at Fish Farm), as well as seaweeds. Though nubbins were detached from the tiles, the tiles remained attached to the grids.

Survivorship and growth parameters. Coral juvenile survivorship and growth (polyp count and spat diameter) were determined with the aid of a stereoscope (Wild M3). Spat area (A) was obtained using the formula $A=\pi(d / 2)^{2}$, where $d$ is the spat diameter. Survival of nubbins was also recorded. Surviving nubbins were cleaned of attached organisms and sediments and weighed using the buoyant weight technique (Jokiel et al. 1978). Growth rates (juvenile polyp count, spat area and nubbin buoyant weight) were deter- mined by dividing the difference of initial and final measurements by the duration of deployment $(2.7 \mathrm{mo})$. Nubbin growth rates were normalized to the initial weights.

For mature colonies, partial mortality (sensu Nugues \& Roberts 2003a,b) was quantified using a 6 class mortality scheme $(0,1-25,26-50,51-75,76-99$, and $100 \%$ ). To obtain a single measure of colony mortality for each site, a colony mortality index (CMI) was calculated, following the bleaching and mortality index described by McClanahan et al. (2004). Using the percentage occurrence (a) of the 6 mortality classes, CMI was calculated with the formula CMI $=\left(0 a_{0}+1 a_{1-25}+\right.$ $\left.2 a_{26-50}+3 a_{51-75}+4 a_{76-99}+5 a_{100}\right) / 5$. This index has a 0 to 100 scale, with 100 indicating total mortality of colonies at a specific site.

Physiological and reproductive measurements. Photosynthesis and respiration measurements were conducted on branch tips (ca. $2 \mathrm{~cm}$ ) of field-exposed mature colonies using the method described above for water productivity. Tips were incubated in $300 \mathrm{ml}$ DO bottles filled with site-collected water. Gross photosynthesis-respiration ratios $\left(\mathrm{P}_{\mathrm{g}}: \mathrm{R}\right)$ for $24 \mathrm{~h}$ were calculated using a 10:14 h light:dark regime. Here total photosynthetic output for each day is assumed to be equivalent to $10 \mathrm{~h}$ of maximum photosynthesis (the day length at the site during the experimental period was ca. $13 \mathrm{~h}$ ). Respiration is assumed constant throughout the diurnal cycle. Physiological data were normalized to surface area as determined using the wax method (Stambler et al. 1991).

Termination of field exposure was timed to the lunar peak in planulation of the species. From each site (except Fish Farm, where most mature colonies died), 4 to 5 colonies were individually monitored for larval release for 5 consecutive days (lunar days 8 to 12). Monitored colonies from Lucero and Reference fell into the $0 \%$ mortality class while those from Tomasa fell into the 26-50\% mortality class. Larval collection was conducted as described above with site-collected water as the static incubation medium.

Statistical analyses. To determine significant differences in environmental factors between sites, the Kruskal-Wallis test with a $\chi^{2}$ approximation was employed. ANOVA was applied to detect significant differences in coral growth, physiological and reproductive parameters among sites. Data were square root transformed where necessary to satisfy the parametric assumptions of normality (Shapiro-Wilk's test) and homoscedasticity (Bartlett's test). Where significant differences were obtained, Duncan's multiple-range test was performed. Data that did not satisfy the parametric assumptions were analysed using KruskalWallis ANOVA. The statistical procedures mentioned above were conducted using the SAS statistical pack- 
age (SAS Institute). The nonparametric Tukey-type multiple comparisons test (Zar 1984) was carried out as a post hoc procedure where the Kruskal-Wallis test rejected the null hypothesis. Fisher's Exact Test was performed to detect differences in the survivorship of coral juveniles and nubbins between pairs of sites. Site differences in frequency distributions of partial mortality were determined using the Kolmogorov-Smirnov 2sample test (Siegel 1956). Results are presented as averages $\pm \mathrm{SD}$, unless indicated otherwise.

\section{RESULTS}

\section{Environmental factors}

Most of the environmental parameters varied significantly among the sites (Fig. 2). In April 2004 sedimentation was highest at Fish Farm (193 $\left.\mathrm{g} \mathrm{m}^{-2} \mathrm{~d}^{-1}\right)$, which was 3-, 16- and 8-fold higher than at Tomasa, Lucero and Reference sites, respectively. The same order in sedimentation intensity among the sites (except for the
Reference) was observed in May. This spatial trend was also obtained for the POM flux, total suspended solids and nutrient concentrations (ammonium and phosphate). The reference site featured a slightly higher sedimentation rate and POM flux compared to either Tomasa or Lucero for the May sample. However, nutrient levels were consistently lower at Reference than either Tomasa or Lucero during both months.

The spatial trend in water column productivity (net photosynthesis) among the sites was Fish Farm > Tomasa $=$ Lucero $>$ Reference (Fig. 2). Water column respiration was higher at Tomasa than Lucero or Reference, where almost negligible values were obtained. High variability in respiration was observed for the water collected at Fish Farm. The trend in DO levels was Fish Farm < Tomasa $<$ Lucero = Reference in May (values at Lucero were higher than at the Reference in June).

Water transparency at Fish Farm was the lowest of all the sites on both monitoring dates. In May, surface irradiance was attenuated from a value of $1500 \mu \mathrm{E} \mathrm{m} \mathrm{m}^{-2}$ $\mathrm{s}^{-1}$ to ca. $90 \mu \mathrm{E} \mathrm{m} \mathrm{m}^{-2} \mathrm{~s}^{-1}$ at $2 \mathrm{~m}$ depth, representing a 17 -fold decrease, as compared to 4-, 1.8- and 1.3-fold
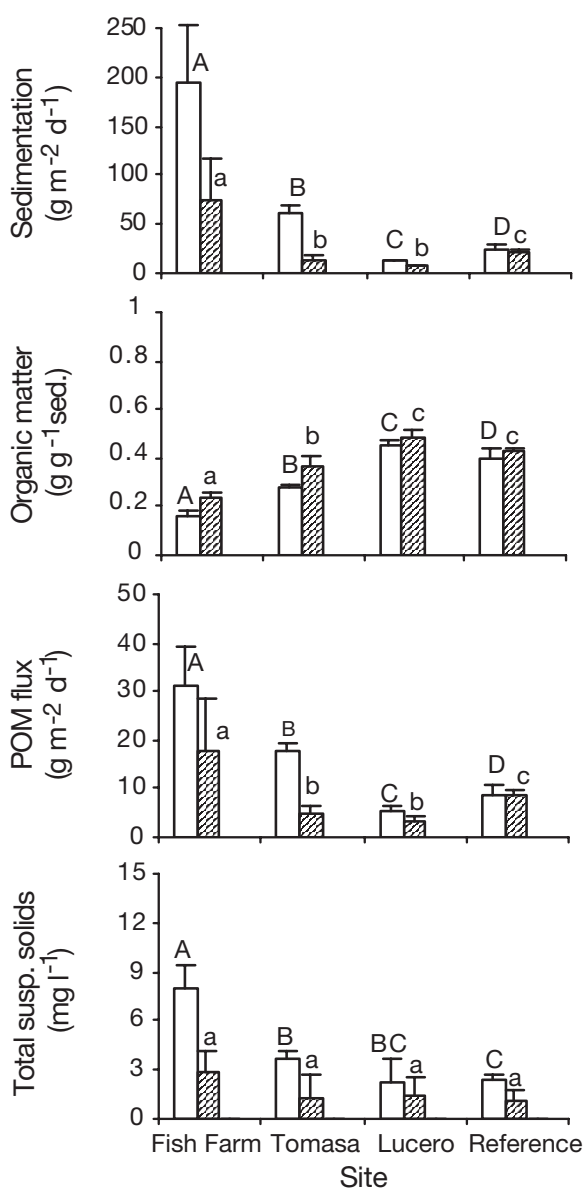
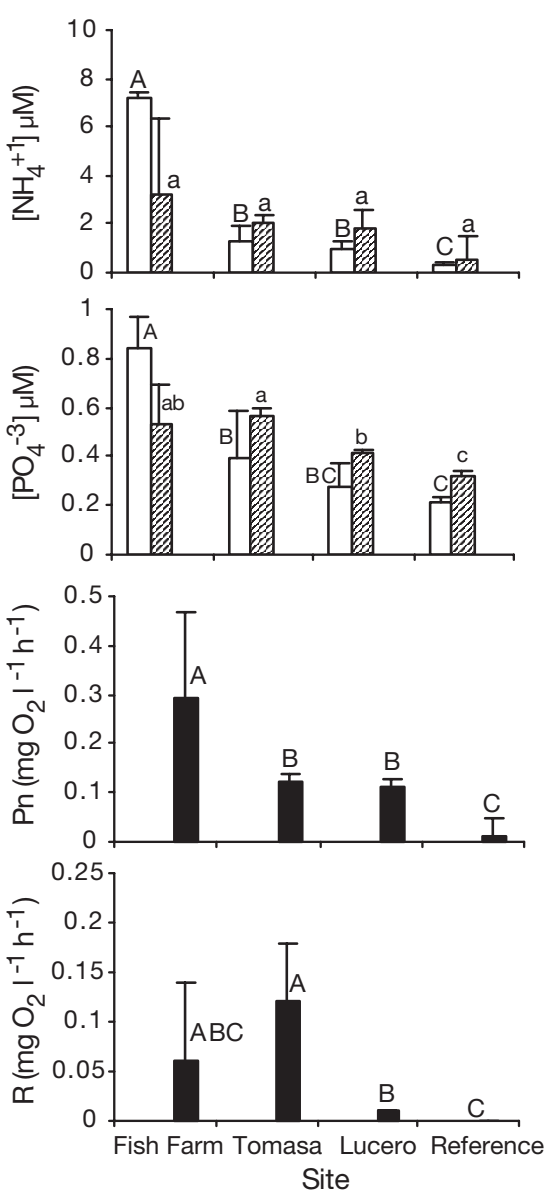

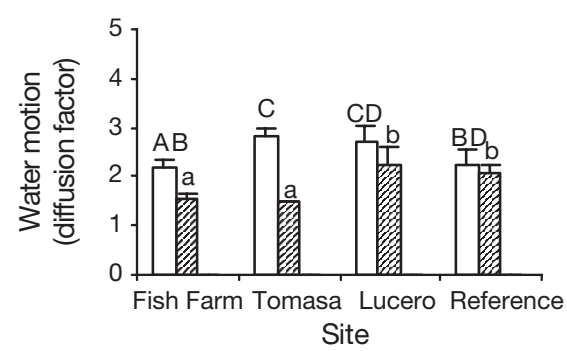

April May $\square$ June 2004

Fig. 2. Environmental factors at the study sites (means $\pm \mathrm{SD}, \mathrm{n}=3$ ). Different letters above bars indicate differences among sites (Kruskal-Wallis test, $\mathrm{p}<0.05$ ); upper case for the first sample and lower case for the second sample 
Table 1. Pocillopora damicornis. Survival and growth rates of juveniles deployed at different sites along a gradient of fish farm effluent (Fish Farm, Tomasa and Lucero; in order of decreasing exposure) and their natal reef (Reference). Juvenile growth measured by polyp count and spat area. $\mathrm{n}_{\mathrm{D}}=$ number of deployed juveniles; $n_{R}=$ number of retrieved juveniles; $\mathrm{S}=$ number of survivors (survival rate, \%)

\begin{tabular}{|c|c|c|c|c|c|}
\hline Site & $\mathrm{n}_{\mathrm{D}}$ & $\mathrm{n}_{\mathrm{R}}$ & S & $\begin{array}{l}\text { Juvenile gr } \\
\text { Polyp count } \\
\text { (polyp mo }{ }^{-1} \text { ) }\end{array}$ & $\begin{array}{l}\text { owth rate } \\
\text { Spat area } \\
\left(\mathrm{mm}^{2} \mathrm{mo}^{-1}\right)\end{array}$ \\
\hline Fish Farm & 30 & 30 & $0(0)$ & - & - \\
\hline Tomasa & 30 & 30 & $0(0)$ & - & - \\
\hline Lucero & 30 & 21 & 4 (19) & $4.4 \pm 5.2$ & $3.4 \pm 3.9$ \\
\hline Reference & 30 & 29 & $5(17)$ & $1.6 \pm 2.3$ & $3.7 \pm 6.1$ \\
\hline
\end{tabular}

Table 2. Pocillopora damicornis. Survival and growth rates of nubbins deployed at different sites along a gradient of fish farm effluent (sites as in Table 1). Nubbin growth measured by buoyant weight. $\mathrm{n}_{\mathrm{D}}=$ number of deployed nubbins; $\mathrm{n}_{\mathrm{R}}=$ number of retrieved nubbins; $\mathrm{S}=$ number of survivors (survival rate, \%). Letters after growth rate values indicate grouping from Duncan's multiple range test $(\alpha=0.05)$

\begin{tabular}{|lcccc|}
\hline Site & $\mathrm{n}_{\mathrm{D}}$ & $\mathrm{n}_{\mathrm{R}}$ & $\mathrm{S}$ & $\begin{array}{c}\text { Nubbin growth rate } \\
\left(\mathrm{g} \mathrm{g}^{-1} \mathrm{mo}^{-1}\right)\end{array}$ \\
\hline Fish Farm & 90 & 17 & $0(0)$ & - \\
Tomasa & 90 & 82 & $26(32)$ & $0.18 \pm 0.11 \mathrm{~A}$ \\
Lucero & 90 & 41 & $41(100)$ & $0.31 \pm 0.18 \mathrm{~B}$ \\
Reference & 90 & 52 & $51(98)$ & $0.37 \pm 0.17 \mathrm{~B}$ \\
\hline
\end{tabular}

decreases at Tomasa, Lucero and Reference, respectively.

There was little variation in water motion (Fig. 2; Kruskal-Wallis ANOVA April: $\chi^{2}=7.54, \mathrm{p}=0.0566$; May: $\chi^{2}=8.74, p=0.0329$ ), or salinity levels (April: $\chi^{2}=$ 2.75, $\mathrm{p}=0.4318$; May: $\chi^{2}=0.00, \mathrm{p}=1.000$; April: 34 to 35\%; May: 34\%o) among the sites during either sampling month.

\section{Coral survivorship}

No juvenile corals survived after the experimental deployment at Fish Farm or Tomasa (Table 1). All of the tiles with coral juveniles at Fish Farm had an estimated average barnacle cover of $80 \%$ of tile surface area. Additionally, barnacles overgrew all corals. The largest barnacle recruit had a diameter of $15 \mathrm{~mm}$, surface area coverage of $177 \mathrm{~mm}^{2}$ and growth rate of $66 \mathrm{~mm}^{2} \mathrm{mo}^{-1}$ (assuming recruitment on the first day of tile deployment). Barnacle recruits were observed on tiles deployed at Tomasa, but with less coverage $(\leq 10 \%)$. Muddy sediment covered tiles from both sites, although thicker at Fish Farm. Juvenile corals survived at Lucero and Reference (though rates were $<20 \%$,
Table 1) with no significant difference between them (Fisher Exact Test, $\mathrm{p}=0.71$ ). No barnacle recruits were observed on the tiles from Lucero and Reference sites, but tiles were covered by short stands of filamentous and fleshy macroalgae (e.g. Polysiphonia-like, Spyridia filamentosa and Ulva reticulata) and some patches of crustose coralline algae.

No coral nubbins survived at Fish Farm, while low nubbin survivorship was recorded at Tomasa (Table 2). The nubbin survival rates at Lucero and Reference sites were comparatively high (Table 2), with no significant difference between them (Fisher's Exact Test, $p=1$ ). Rates from both sites were significantly different from Fish Farm and Tomasa (Fisher's Exact Test, p < 0.0001).

Occurrences of partial mortality in mature colonies deployed at the 4 sites are presented in Fig. 3. About $90 \%$ of those at Fish Farm suffered total mortality. Only the branch tips survived in the remainder (i.e. categorized as 76 to $99 \%$ mortality). A high percentage of mature colonies also suffered total mortality at Tomasa. In contrast, low values were observed at Lucero and Reference with no significant difference in partial mortality class frequency distribution between them (Fig. 3). The calculated CMI values were: Fish Farm $=97.4 ;$ Tomasa $=77.7 ;$ Lucero, $21.4=$ and Refer ence $=21.9$.

\section{Coral juvenile and nubbin growth}

There was no significant difference in growth rates of surviving coral juveniles between Lucero and Reference (Table 1 ; ANOVA; polyp count: $F=0.68, \mathrm{p}=$ 0.4414 ; spat area: $F=0.11, p=0.7550)$. Nubbin growth

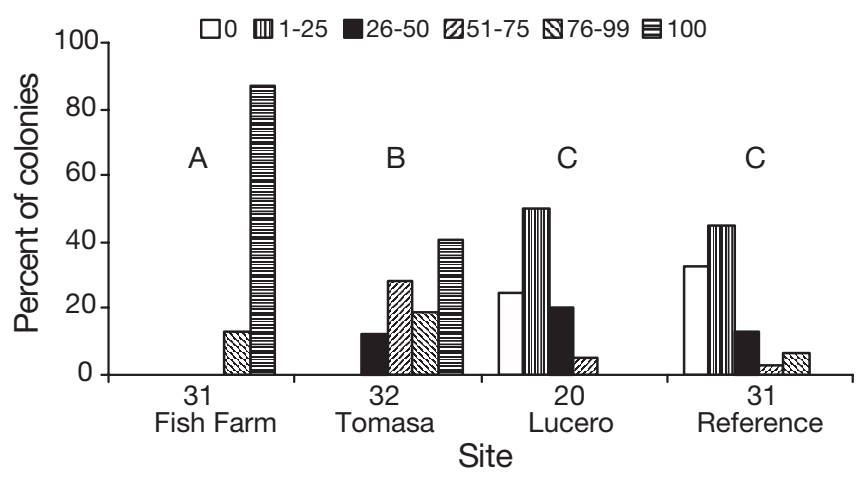

Fig. 3. Pocillopora damicornis. Frequency distributions of partial mortality in mature coral colonies deployed at each study site. Partial mortality (\%) classes are denoted in the legend. Numbers above site names indicate sample sizes. Partial mortality class frequency distributions not significantly different have the same letters (Kolmogorov-Smirnov 2-sample test, $\mathrm{p}>0.05$ ) 
rates varied significantly among sites where survivors were recovered (Table 2; ANOVA, $F=11.22$, p < 0.0001). Growth rates of nubbins were significantly lower in Tomasa compared to those deployed at either Lucero or Reference, with the latter 2 sites exhibiting no statistically significant difference (Table 2).

\section{Larval metamorphosis}

No metamorphosis or death was observed after $48 \mathrm{~h}$ in the control units (in the absence of SCS or $\mathrm{SCT}$ and in the presence of unconditioned tiles). The rates of metamorphosis of Pocillopora damicornis larvae varied significantly on substrates from different sites (Fig. 4) (Kruskal-Wallis ANOVA; SCS: $\chi^{2}=$ 28.85, $\mathrm{p}<0.0001$; SCT: $\left.\chi^{2}=13.05, \mathrm{p}=0.0045\right)$. Very low percentages of metamorphosis (means of $<5 \%$ ) were recorded on SCS from Fish Farm and Tomasa (Fig. 4), which did not differ significantly from the controls (Kruskal-Wallis ANOVA; $\chi^{2}=1.00, \mathrm{p}=$ $0.3173 ; \chi^{2}=2.11, p=0.1468$, respectively). On the other hand, SCS from the Reference site apparently induced metamorphosis in up to about $70 \%$ of larvae, which is significantly higher than values from other sites, except Lucero (Fig. 4). The metamorphic response of $P$. damicornis larvae on SCT from Tomasa is intermediate between those from Fish Farm and Lucero/Reference (Fig. 4).

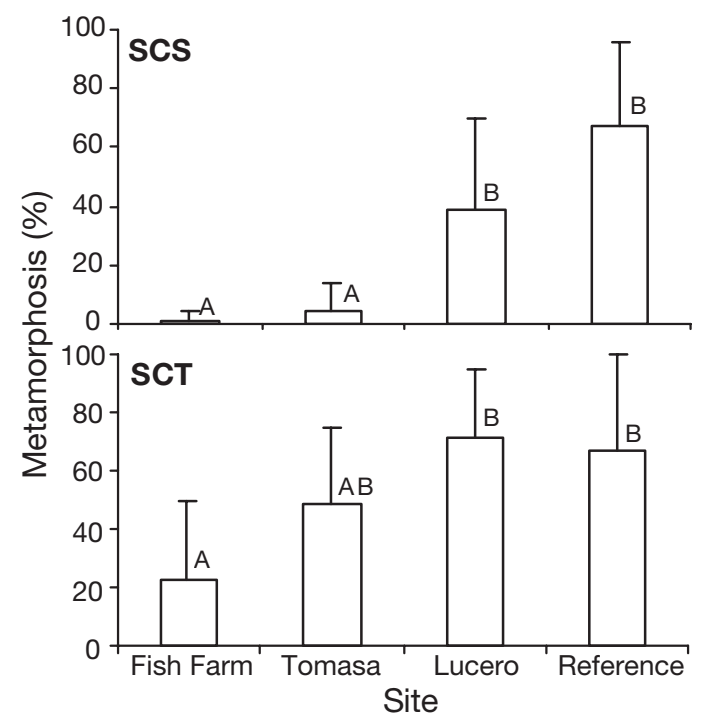

Fig. 4. Pocillopora damicornis. Larval metamorphosis in sitecollected substrates (SCS) and site-conditioned terracotta tiles $(\mathrm{SCT})$; mean $\pm \mathrm{SD}, \mathrm{n}=10$. No metamorphosis or death was observed after $48 \mathrm{~h}$ in the control units, i.e. without substrates or tiles and with new, unconditioned tiles. Same letter indicates no significant difference (nonparametric Tukeytype multiple comparisons, $\mathrm{p}>0.05$ )

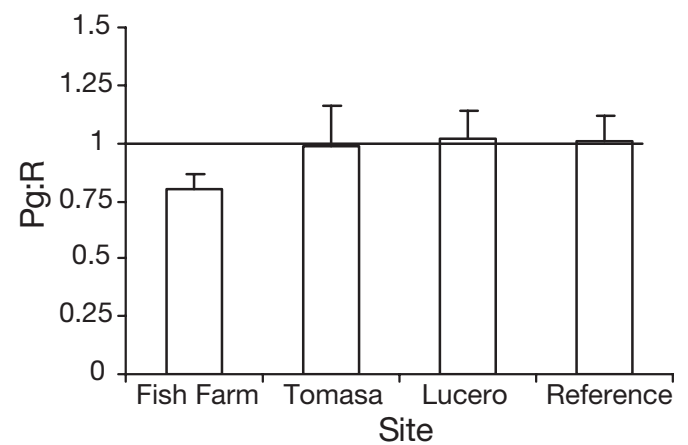

Fig. 5. Pocillopora damicornis. Gross production (Pg) to respiration $(\mathrm{R})$ ratios of corals previously deployed at different sites, incubated in site-collected water; mean $\pm \mathrm{SD}, \mathrm{n}=3$. Horizontal line denotes Pg:R value of 1.0 (the physiological compensatory value)

\section{Physiological and reproductive parameters}

Respiratory measurements showed lower Pg:R values in corals deployed at Fish Farm compared to those deployed at the other sites (Fig. 5), although there were no significant differences in $\mathrm{Pg}: \mathrm{R}$ among sites (Kruskal-Wallis ANOVA, $\chi^{2}=3.54, p=0.3160$ ). The $\mathrm{Pg}: \mathrm{R}$ value obtained for Fish Farm deployed corals $(0.8 \pm 0.07)$ was $<1$, while those from other sites approximated unity (Fig. 5).

No reproductive measurement for Fish Farm deployed mature colonies was conducted due to the high mortality in the $81 \mathrm{~d}$ experiment. Only 1 out of 4 or 5 of the monitored colonies from Tomasa and Lucero underwent planulation, with very low larval output (1 or 2 larvae). In contrast, all colonies retrieved from the Reference site planulated with larval output ranging from 9 to 191 (average of 60) per colony, significantly higher than those from colonies deployed at either Tomasa (Kruskal-Wallis ANOVA; $\chi^{2}=6.26, \mathrm{p}=$ 0.0123 ) or Lucero $\left(\chi^{2}=7.31, \mathrm{p}=0.0069\right)$.

\section{DISCUSSION}

We demonstrated that exposure to effluent from intensive fish farming causes adverse effects on different life stages of a reef-building coral. At the larval stage metamorphosis was diminished on substrates collected from the Fish Farm site, on tiles conditioned in the same environment, and at the site receiving intermediate concentrations of fish farm effluent. The limited larval metamorphosis on substrates near intensive fish farming may be caused by the absence of essential surface biota that provide chemical cues for metamorphosis (e.g. crustose coralline algae, CCA; Heyward \& Negri 1999), and/or the presence of sediment deposits on the substrates that prevent firm 
attachment of the larvae. Coral larvae do not metamorphose on loose or fine sediments (Hodgson 1990). For those treatments containing tiles and substrates from the sites far from the fish farms, some larvae underwent metamorphosis on the walls of the culture vessel. This implies that metamorphic cues from surface biota on the substrates or tiles were released into the water, and metamorphosis was able to proceed on any hard substrate available. Coverage by metamorphosis inducing CCA is low at eutrophic reefs (Hunte \& Wittenberg 1992). We observed no CCA on the tiles and substrates retrieved from Fish Farm, while these were present on those from sites further away.

This study has shown that even if coral larvae succeeded in settling and metamorphosing near or at the fish farms, juvenile survival is nil. Previously, we demonstrated the total mortality of juveniles of another reef-building coral (Seriatopora caliendrum) deployed for $40 \mathrm{~d}$ in a fish farm environment (Villanueva et al. 2005). Total juvenile mortality is caused by sediment burial and overgrowth by fast growing encrusting organisms (particularly barnacles) whose recruitment and growth are apparently enhanced by the fish farm environment. At sites with minimal or no exposure to fish farm effluent spat survivorship was still low. High post-settlement mortality of newly settled corals in their natural environment has previously been reported (Babcock 1985, Sato 1985, Wilson \& Harrison 2005). The post-settlement stage is critical in the life history of a coral. Consequently, stress such as exposure to fish farm effluent has the potential to cause recruitment failure.

Coral nubbins are sensitive tools for ecotoxicological studies (Davies 1990, 1995). The trend in nubbin survivorship in sites along a gradient of fish farm effluent exposure indicates that the latter is detrimental to the reef-building coral Pocillopora damicornis. At the site of intermediate exposure, surviving nubbins had growth rates half of those at the site of minimal influence, and at the reference site. Among the 3 sites of different effluent concentrations, both nubbin survivorship and growth rate increased with decreasing exposure. Nubbin survivorship and growth rate at the site of minimal influence were similar to those deployed at the Reference site.

For mature stages of the coral Pocillopora damicornis, exposure to effluent from intensive fish farming can cause increased colony mortality. Sediment burial and overgrowth by fast-growing organisms are less likely to affect the coral colonies at these stages due to their greater size (and profile). However, other stress vectors related to exposure to effluent (e.g. nutrification, diminished water transparency and lowered levels of DO) could have operated individually or in concert to grossly impair their physiological capacity.
The mean Pg:R value obtained for the coral branches previously deployed at Fish Farm and incubated in site-collected seawater was below the physiological compensatory value of 1 . The experimental measurement of this value was done at light levels above the photosynthetic saturation of ca. $400 \mu \mathrm{E} \mathrm{m} \mathrm{m}^{-2} \mathrm{~s}^{-1}$ (Chalker et al. 1983). However, at Fish Farm we measured a light level of about $90 \mu \mathrm{E} \mathrm{m} \mathrm{m}^{-2} \mathrm{~s}^{-1}$ at platform depth (from a surface irradiance of about $1500 \mu \mathrm{E} \mathrm{m} \mathrm{m}^{-2}$ $\mathrm{s}^{-1}$ at around midday). Hence, the in situ Pg:R value at Fish Farm is projected to depart even more from the compensatory value. Likewise, at Tomasa, the site receiving intermediate effluent concentrations, irradiance level was also lower than the level for photosynthetic saturation during one of our monitoring runs (ca. $300 \mu \mathrm{E} \mathrm{m}^{-2} \mathrm{~s}^{-1}$ in May from a surface irradiance of $1250 \mu \mathrm{E} \mathrm{m}^{-2} \mathrm{~s}^{-1}$ ). In contrast, light levels were always $>400 \mu \mathrm{E} \mathrm{m}^{-2} \mathrm{~s}^{-1}$ at Lucero and Reference during the 2 monitoring runs.

It has been suggested that corals at low light conditions will derive progressively more nutrition from heterotrophy (Anthony \& Fabricius 2000, Titlyanov et al. 2000). The diminished photosynthesis at and near the Fish Farm may then be compensated by heterotrophy through suspension feeding, especially with the increase in suspended solids. Aside from the conventional animate particulates they ingest through suspension feeding (Yonge 1930), corals can feed on sediment and fine particulate matter (Anthony 1999, Rosenfeld et al. 1999), and consume dissolved organic matter (Sorokin 1973). The enhanced growth of corals at the fish farms in Eilat, Red Sea has been attributed to the elevated organic matter that serves as an additional food source in hyper-oligotrophic waters (Bongiorni et al. 2003b). In this study, however, enhanced heterotrophy cannot compensate for the physiological stress caused by the fish farm effluent, as demonstrated by elevated coral mortality.

Nutrient enrichment derived from fish farms is detrimental to coral reproduction, with failure in oocyte maturation, fertilization and ensuing larval development (Loya et al. 2004). We observed diminished larval output in mature colonies of the brooding coral Pocillopora damicornis after almost 3 mo of experimental deployment in sites receiving intermediate and minimal concentrations of fish farm effluent. No reproductive measurement was conducted for colonies deployed at Fish Farm due to high mortality. Reproduction in $P$. damicornis occurs throughout the year, but with lunar periodicities (Fan \& Dai 2003). A complete reproductive cycle spans about 2 lunar cycles (deduced from Diah Permata et al. 2000, Fan \& Dai 2003). The duration of effluent exposure in this study covered approximately 3 lunar cycles. Since we selected for our reproductive measurements only those 
colonies (from Lucero) incurring no partial mortality, obvious tissue damage or bleaching, we could not apply the paradigm of reproduction-regeneration trade off in damaged corals (sensu Rinkevich 1996). However, this trade off may have operated in the Tomasa colonies, which exhibited 26 to $50 \%$ mortality. The higher partial mortality in colonies near fish farms will also lessen the number of polyps that could contribute to larval production.

We have demonstrated deterioration in the health of reef-building coral with decreasing distance to an intensive mariculture facility. Such a spatial pattern in coral health is caused by the variation in water quality associated with fish farm effluent concentrations among the sites where corals were experimentally deployed. The tremendous increase of sedimentation and eutrophication at Fish Farm produced detrimental effects on different coral life stages. Together with associated environmental parameters (reduced water transparency and DO levels) sedimentation and eutrophication are recognized stressors impairing coral physiology and reproduction and diminishing survivorship. Furthermore, successful recruitment of fast growing encrusting invertebrates, particularly barnacles, led to competition with or fouling of coral juveniles and low profile coral recruits. Metamorphosis of coral larvae was also limited in the Fish Farm environment, most probably due to the absence of essential biota (e.g. CCA) as sources of chemical metamorphic cues. Hence, many aspects of the biology and ecology of a reef-building coral are impaired by intensive fish farming. There was little variation between sites in physico-chemical parameters not associated with fish farming, e.g. water motion and salinity-environmental factors that also potentially influence coral biology (Jokiel 1978, Ferrier-Pagés et al. 1999).

The effects of massive organic loading from fish farms is not restricted to reef corals; seagrasses are also threatened (Ruiz et al. 2001). In order to reduce negative environmental impacts of intensive aquaculture activities an emerging management solution that employs an integrated mariculture scheme involving fed and extractive (usually seaweeds) organisms (Chopin et al. 2001, Neori et al. 2004) has been proposed. However, the use of seaweeds as extractive organisms will only mitigate the eutrophication aspect of the effluent's impact. Sedimentation may be managed by the inclusion of filter feeders such as mussels into fish cultures. Unfortunately, few cases of integrated experiments of this kind have resulted in the expected reduction in suspended solids. Particle retention may be limited by some threshold level related to the handling of fish farm solid wastes by mussels (Troell \& Norberg 1998).

Another possible solution to organic loading is the construction of artificial reefs below fish farms to act as biofilters (with the action of fouling invertebrates, algae and bacteria), but expected results are not evident over short time scales (Angel \& Spanier 2002). Recently prohibition of fishing of large planktivorous fishes around sea-cage fish farms has been suggested (Dempster et al. 2005), as these fishes consume particulate organic wastes (Vita et al. 2004), thereby ameliorating benthic impacts. Indeed, more management solutions should be developed in order to attain environmental sustainability in mariculture areas, as support to the rising global demand for seafood.

Acknowledgements. We thank M. Ponce and R. T. Dizon for field and laboratory assistance, and H. G. Bangi for use of the field DO meter. Y. Loya and 3 anonymous reviewers provided valuable comments. This study formed part of R.D.V.'s PhD dissertation. Dissertation funding was provided by Shell Philippines Exploration B.V. This is contribution no. 350 of the Marine Science Institute (University of the Philippines).

\section{LITERATURE CITED}

Angel DL, Spanier E (2002) An application of artificial reefs to reduce organic enrichment caused by net-cage fish farming: preliminary results. ICES J Mar Sci 59:S324-S329

Anthony KRN (1999) Coral suspension feeding on fine particulate matter. J Exp Mar Biol Ecol 232:85-106

Anthony KRN, Fabricius KE (2000) Shifting roles of heterotrophy and autotrophy in coral energetics under varying turbidity. J Exp Mar Biol Ecol 252:221-253

Babcock RC (1985) Growth and mortality in juvenile corals (Goniastrea, Platygyra and Acropora): the first year. Proc 5th Int Coral Reef Congr 4:355-360

Bongiorni L, Shafir S, Rinkevich B (2003a) Effects of particulate matter released by a fish farm (Eilat, Red Sea) on survival and growth of Stylophora pistillata coral nubbins. Mar Pollut Bull 46:1120-1124

Bongiorni L, Shafir S, Angel D, Rinkevich B (2003b) Survival, growth and gonad development of two hermatypic corals subjected to in situ fish-farm nutrient enrichment. Mar Ecol Prog Ser 253:137-144

Chalker BE, Dunlap WC, Oliver JK (1983) Bathymetric adaptations of reef-building corals at Davies Reef, Great Barrier Reef, Australia. II. Light saturation curves for photosynthesis and respiration. J Exp Mar Biol Ecol 73:37-56

Chopin T, Buschmann AH, Halling C, Troell M and 6 others (2001) Integrating seaweeds into marine aquaculture systems: a key toward sustainability. J Phycol 37:975-986

Davies PS (1990) A rapid method for assessing growth rates of corals in relation to water pollution. Mar Pollut Bull 21: 346-348

Davies PS (1995) Coral nubbins and explants for reef assessment and laboratory ecotoxicology. Coral Reefs 14:267269

Dempster T, Fernandez-Jover D, Sanchez-Jerez P, Tuya F, Bayle-Sempere J, Boyra A, Haroun RJ (2005) Vertical variability of wild fish assemblages around sea-cage fish farms: implications for management. Mar Ecol Prog Ser 304:15-29

Diah Permata W, Kinzie RA III, Hidaka M (2000) Histological studies on the origin of planulae of the coral Pocillopora damicornis. Mar Ecol Prog Ser 200:191-200

Doty MS (1971) Measurement of water movement in reference to benthic algal growth. Bot Mar 14:32-35 
Epstein N, Bak RPM, Rinkevich B (2001) Strategies for gardening denuded coral reef areas: the applicability of using different types of coral material for reef restoration. Restor Ecol 9:432-442

Fabricius KE (2005) Effects of terrestrial runoff on the ecology of corals and coral reefs: review and synthesis. Mar Pollut Bull 50:125-146

Fan TY, Dai CF (2003) Sexual reproduction of the reef coral Pocillopora damicornis in southern Taiwan. Acta Oceanogr Taiwan 41:1-12

Ferrier-Pagès C, Gattuso JP, Jaubert J (1999) Effect of small variations in salinity on the rates of photosynthesis and respiration of the zooxanthellate coral Stylophora pistillata. Mar Ecol Prog Ser 181:309-314

Hadfield MG, Paul VJ (2001) Natural chemical cues for settlement and metamorphosis of marine invertebrate larvae. In: McClintock JB, Baker BJ (eds) Marine chemical ecology. CRC Press, Boca Raton, p 431-461

Hansen HP, Koroleff F (1999) Determination of nutrients. In: Grasshoff K, Kremling K, Ehrhardt M (eds) Methods of seawater analysis. Wiley-VCH, Weinheim, p 157-228

Heyward AJ, Negri AP (1999) Natural inducers for coral larval metamorphosis. Coral Reefs 18:273-279

Hodgson G (1990) Sediment and the settlement of larvae of the reef coral Pocillopora damicornis. Coral Reefs 9:41-43

Hughes TP, Baird AH, Bellwood DR, Card M and 13 others (2003) Climate change, human impacts, and the resilience of coral reefs. Science 301:929-933

Hunte W, Wittenberg M (1992) Effects of eutrophication and sedimentation on juvenile corals. II. Settlement. Mar Biol 114:625-631

Jokiel PL (1978) Effects of water motion on reef corals. J Exp Mar Biol Ecol 35:87-97

Jokiel PL, Maragos JE, Franzisket L (1978) Coral growth: buoyant weight technique. In: Stoddart DR, Johannes RE (eds) Coral reefs: research methods. UNESCO, Paris, p 529-541

Koop K, Bootii D, Broadbent A, Brodie J and 16 others (2001) ENCORE: the effect of nutrient enrichment on coral reefs. Synthesis of results and conclusions. Mar Pollut Bull 42: 91-120

Loya Y, Kramarsky-Winter E (2003) In situ eutrophication caused by fish farms in the northern Gulf of Eilat (Aqaba) is beneficial for its coral reefs: a critique. Mar Ecol Prog Ser 261:299-303

Loya Y, Lubinevsky H, Rosenfeld M, Kramarsky-Winter E (2004) Nutrient enrichment caused by in situ fish farms at Eilat, Red Sea is detrimental to coral reproduction. Mar Pollut Bull 49:344-353

Loya Y, Rosenfeld M, Kramarsky-Winter E (2005) Nutrient enrichment and coral reproduction: empty vessels make the most sound (response to a critique by B. Rinkevich). Mar Pollut Bull 50:114-118

McClanahan TR, Baird AH, Marshall PA, Toscano MA (2004) Comparing bleaching and mortality responses of hard corals between southern Kenya and the Great Barrier Reef, Australia. Mar Pollut Bull 48:327-335

McManus JW, Nañola CL Jr, Reyes RB Jr, Kesner KN (1992) Resource ecology of the Bolinao coral reef system. ICLARM Stud Rev 22, ICLARM, Manila

Neori A, Chopin T, Troell M, Buschmann AH, Kraemer GP, Halling C, Shpigel M, Yarish C (2004) Integrated aquaculture: rationale, evolution and state of the art emphasizing seaweed biofiltration in modern mariculture. Aquaculture 231:361-391

Editorial responsibility: Otto Kinne (Editor-in-Chief), Oldendorf/Luhe, Germany
Nugues MM, Roberts CM (2003a) Coral mortality and interaction with algae in relation to sedimentation. Coral Reefs 22:507-516

Nugues MM, Roberts CM (2003b) Partial mortality in massive reef corals as an indicator of sediment stress on coral reefs. Mar Pollut Bull 46:314-323

Nyström M, Folke C, Moberg F (2000) Coral reef disturbance and resilience in a human-dominated environment. Trends Ecol Evolut 15:413-417

Pandolfi JM, Bradbury RH, Sala E, Hughes TP and 8 others (2003) Global trajectories of the long-term decline of coral reef ecosystems. Science 301:955-958

Rinkevich B (1996) Do reproduction and regeneration in damaged corals compete for energy allocation? Mar Ecol Prog Ser 143:297-302

Rinkevich B (2005) Nutrient enrichment and coral reproduction: between truth and repose (a critique of Loya et al.). Mar Pollut Bull 50:111-113

Rinkevich B, Angel D, Shafir S, Bongiorni L (2003) 'Fair is foul and foul is fair': response to a critique. Mar Ecol Prog Ser 261:305-309

Rogers CS (1990) Responses of coral reefs and reef organisms to sedimentation. Mar Ecol Prog Ser 62:185-202

Rosenfeld M, Bresler V, Abelson A (1999) Sediment as a possible source of food for corals. Ecol Lett 2:345-348

Ruiz JM, Pérez M, Romero J (2001) Effects of fish farm loadings on seagrass (Posidonia oceanica) distribution, growth and photosynthesis. Mar Pollut Bull 42:749-760

Sato M (1985) Mortality and growth of juvenile coral Pocillopora damicornis (Linnaeus). Coral Reefs 4:27-33

Siegel S (1956) Nonparametric statistics for the behavioral sciences. McGraw-Hill Kogakusha, Tokyo

Sorokin YI (1973) On the feeding of some scleractinian corals with bacteria and dissolved organic matter. Limnol Oceanogr 18:380-385

Stambler N, Popper N, Dubinsky Z, Stimson J (1991) Effects of nutrient enrichment and water motion on the coral Pocillopora damicornis. Pac Sci 45:299-307

Titlyanov EA, Leletkin VA, Dubinsky Z (2000) Autotrophy and predation in the hermatypic coral Stylophora pistillata in different light habitats. Symbiosis 29:263-281

Troell M, Norberg J (1998) Modelling output and retention of suspended solids in an integrated salmon-mussel culture. Ecol Model 110:65-77

Udarbe-Walker MJ, Magdaong E (2003) Circulation and hydrographic characteristics of a mariculture area northwest of Lingayen Gulf. Philipp Scientist 40:57-72

Villanueva RD, Yap HT, Montaño MNE (2005) Survivorship of coral juveniles in a fish farm environment. Mar Pollut Bull 51:580-589

Vita R, Marín A, Madrid JA, Jiménez-Brinquis B, Cesar A, Marín-Guirao L (2004) Effects of wild fishes on waste exportation from a Mediterranean fish farm. Mar Ecol Prog Ser 277:253-261

Wielgus J (2003) The coral reef of Eilat (northern Red Sea) requires immediate protection. Mar Ecol Prog Ser 263: 307

Wilson J, Harrison P (2005) Post-settlement mortality and growth of newly settled reef corals in a subtropical environment. Coral Reefs 24:418-421

Yonge CM (1930) Studies on the physiology of corals. I. Feeding mechanisms and food. Sci Rep Great Barrier Reef Exped 1928-29 1:13-61

Zar JH (1984) Biostatistical analysis. Prentice-Hall, Englewood Cliffs, NJ 